\title{
Knowledge as a Value: The Ideas of A-Growth and Commons
}

Nílson José Machado

Full Professor, Department of Teaching Methodology and Comparative Education, School of Education, University of São Paulo.

E-mail: njmachad@usp.br

\section{KNOWLEDGE AND VALUE}

Knowledge is a primary good and its value has always been recognized, at all times. Nowadays, however, we experience deviant perspectives that contaminate the assignment of value to knowledge. One of them is improper identification of the ideas of knowledge and commodity in an industrial sense. Such a conceptual reduction may be responsible for the apparent imbalances in the circulation of values in today's world, with the excessive wealth concentration on a global basis.
Direct association between knowledge and economics is relatively recent. In Ancient Greece, there was a clear separation between the universes of knowledge and work. Knowledge, episteme, and even the logos were not tied to the artisan's techné or the slave's work. Nowadays, from the $18^{\text {th }}$-century Industrial Revolution until now, such universes got closer, they interpenetrated each other so that they can no longer be clearly separated. Knowledge has objectively become the main production factor.

\section{KNOWLEDGE AS A COMMODITY: LIMITS}

The challenge to consider, however, is the fact that, even without denying its dimension of commodity, knowledge is not limited in such a dimension. Just to illustrate the intrinsic difficulties, we remark that knowledge is an asset that I can give or sell to someone else without running out of it. It is a product that is not fungible: in a sense, the more I use, the newer it becomes. It is a commodity whose stock cannot be controlled, it is not even possible to talk of stock... It is not by chance that almost all books addressing knowledge as an asset in the economic sense include a chapter devoted to inevitable paradoxes in such an accounting.
In fact, the production and circulation of commodities are based on certain principles that are only partially applicable to knowledge or, indeed, they are absolutely not pertinent to this universe. Materiality, fungibility, objectification, ability to be stocked, trust, and equivalence constitute some grounds where the "commodity" knowledge seems to skid.

How can we control the stock and production of something whose most distinctive characteristic is the permanent overflow of the planned expectations, whose most likely outcome is the production of effects like serendipity, i.e. outcomes that were not initially foreseen?

\section{KNOWLEDGE AND GROWTH: THE JOURNAL ENTROPIA}

It is almost a commonplace: the economic thought seeks growth as a living being seeks air to breathe. For a long time, economics has not paid enough attention to the fact that the materials needed to produce commodities were, to a large extent, non-renewable. An exploratory nomadism led to occasional focus changes. Longer terms in relation to the length of human life suggested, here and there, the expectation of infinite. However, for some time, the constant pursuit of growth is no longer the one-way thought, we came to see on the horizon depletion of resources or valuable materials. Precious metals, oil barrels, strategic substances, everything came to be thought of from the perspective of a limited exploration, a conscious consumption, a sustainable exploration.
A remarkable initiative in this direction took place in France, in 2006. A group of thinkers from various knowledge fields, including philosophy, sociology, economics, politics, anthropology, history, among others, launched a movement named Entropy, embodied in the Revue d'Étude Théorique et Politique de la Decroissance. That is right: a publication dedicated to the theoretical study on decrease. In its first sentences, the initial article (Pourquoi Entropia), the group registers:

Every thought that refuses self-criticism is no longer a thought, but a belief (p. 3).

Of course, the keyword to characterize the group's work might not be de-growth, but rather no growth, or 
a-growth, as Serge Latouche (p. 11) explains, in his initial article in volume 1:

With exceptional rigor, it might be appropriate to speak of the theoretical level of "a-growth", just as we speak of a-theism, rather than de-growth.

The focus of debate is the grounding of an economic discourse that does not situate growth on an uncritical basis as a value in itself, which does not eliminate, but tame the wild capitalism; that is the core of the idea of a-growth.

Despite this, the intention to draw attention overcame the clarity of diagnosis, and the word "de-growth" becomes protagonist in all papers. The group's letter of intent maps four crises to be faced, all of them derived from the one-way thought of growth, according to the authors: energy, climate, social, and cultural. They include in the analyses, indirectly, issues related to knowledge as an economic value, but the reflections focus on other pathways, in which social, political, ethical issues gain more prominence than in other rather specific ones, as those presented herein, regarding epistemology, or the overflow of knowledge from the universe of education, personnel training, that of economics or work. This journal published 16 thematic issues, between 2006 and 2014, when the venture came to an end.

When we think of knowledge as a value in the economic sense, a key aspect in the reflection on a-growth provided by the fruitful experience of the journal Entropia seems to have been put aside. Fair combat to limitless consumerism, the display of luxury goods, the excessive luxury, along with the awareness of finitude and limitation of certain crucial resources do not refer, of course, to restricting access to knowledge as a value. We cannot aim to inhibit the expectation of perfectibility, the continued pursuit of personal growth in terms of wisdom, knowing what is worthwhile. Certainly, the journal did not aim to fight against personal growth as a life purpose; and much less seek any knowledge de-growth, even in merely provocative terms.

\section{KNOWLEDGE AND SHARING: THE IDEA OF COMMONS}

A new insight into the assignment of economic value to knowledge came to light with the work by the political economist Elinor Ostrom. In 2009, she became the first woman to win the Nobel Prize in Economics, due to the study Governing the commons: the evolution of institutions for collective action, later on published by the Cambridge University Press. Therein the idea of commons is explored as opposed to that of commodity, when dealing with certain resources, which should circulate more appropriately through social sharing regimes. Always used in the plural, the word commons had as its references the air, water, internet, scientific knowledge, among others. Having originated from the pen of an economist, the inclusion of knowledge into the category of commons is exciting and inspiring. In her book Understanding knowledge as a commons: from theory to practice, co-written with Charlotte Hess and published by the MIT Press in 2011, Ostrom remarks she seeks

[...] a new way of looking at knowledge as a shared resource, a complex ecosystem that is a commons - a resource shared by a group of people that is subject to social dilemmas (Ostrom \& Hess, 2011, p. 3).

She intends that knowledge, precisely because it is intangible, should be included in the category of a public good, arguing that:

One person's use of knowledge (such as Einstein's Theory of Relativity) did not subtract from another person's capacity to use it (Ostrom \& Hess, 2011, p. 9).
In the work cited, practical aspects of the idea of commons are listed. A particularly relevant aspect is that related to the characterization of authorship a minefield for editors of scientific publications. In every approach to the theme, it becomes clear, however, that the ideas of commons and commodity are not regarded as irreconcilable opponents:

\footnotetext{
Market and commons are synergistic. They interpenetrate each other and perform complementary tasks. Business can flourish only if there is a commons (think of road tasks, sidewalks, and communication channels) that allows private property to be balanced against public needs. Privatize the commons and you begin to stifle commerce, competition and innovation as well as the means to address social and civic needs. To defend the commons is to recognize that human societies have collective needs and identities that the market cannot fulfill by itself (Ostrom \& Hess, 2011, p. 38).
}

The fruitfulness of Ostrom's work lies on the exploring pathways. Her seminal book, just in accordance with her worldview, circulates in bookstores, but it is also freely available on the Internet. Although she has addressed in closer detail practical issues of the circulation of commons in contexts with lack or degradation of resources, her constant attention to knowledge is apparent throughout her work:

Typical threats to knowledge commons are commodification or enclosure, pollution and degradation, and non-sustainability (Ostrom \& Hess, 2011, p. 5). 
Her optimism regarding knowledge is a symptom that there might be space, in her reflection, for a rather specific analysis of knowledge as a value, as suggested, for instance, by the following excerpt:

An infinite amount of knowledge is waiting to be unearthed. The discovery of future knowledge is a com- mon good and a treasure we owe to future generations (Ostrom \& Hess, 2011, p. 8).

Unfortunately, Ostrom died in 2012, in full exercise of an outstanding academic vigor. The fruitfulness of her ideas, however, constitutes a significant inspiration for all those who focus on the theme of knowledge as an economic value.

\section{KNOWLEDGE AS A VALUE: NEW CHALLENGES}

We walked down towards the end of this route. The proposed objective was mapping the key elements for proper treatment of knowledge as a value in economic sense. From the clear separation between the universes of knowledge and work, such as that enforced in the Greek world, until a full interconnection between these universes, such as that occurring today, we came through a space of relations where the conception of knowledge was significantly linked with the ideas of information, commodity, gift, commons, and it also touches many others. The analysis of the possibilities and limits of the interrelations considered aimed at seeking to better understand the nature of this value, which, as a modern sphinx, challenges philosophers, educators, economists, political scientists, among others. We achieve the end of the route with some insights into the initial doubts, derived from inspiring works, explored along the way and, of course, with many other doubts, with many other challenges to be faced in dealing with the economic value of knowledge. We remark, herein, some of these reluctant challenges.

First, anyone who focuses on the theme proposed herein will have to resist simplifying polarizations, such as those suggesting choices involving exclusion between elements of pairs such as information/knowledge, gift/commodity, commodity/commons, among others. Recognizing the complexity of the theme prevents an approach that is restricted to universes limited to binary decisions, as if it was a fairy tale, children's story. Certainly, to run the risk of saying something meaningful, the economic narratives need to take multiple dimensions and the interrelations arising from partial polarizations associated with the issue addressed. The knowledge is made by information, but it is not enough to gather them. Although it may be sold or exchanged, it only circulates in a fruitful way when gifted relations are established between people. And a continued quest for it is rather linked to the fair intent of personal development than to mere accounting purposes of growing its gross value.

A second challenge to be faced is examining more slowly the new issues that are put in the scenario, originated from the omnipresence and the increasing important role played by information technology in productive processes, especially in knowledge construction. A symptom of the little attention paid to such issues is the fact that we address databases as if they were information and we address information as if they were knowledge. When evaluating databases, circulating information, or theoretical knowledge on any theme, we often resort to a binary unit, the bit. The bit, however, is a convenient unit for measuring the extension of a database or to evaluate the amount of information of a message, by taking into account only the frequency with which it occurs, regardless of the context where it takes place. A message whose content can be identified by a single question having a binary nature, i.e. "is it or is not it?", has exactly one bit of information. If the message is more complex and we need $n$ binary questions to identify it, so it has $n$ bits. When we take into account, in addition to the frequency of occurrence, the message meaning or its content, then the bit is no longer a suitable unit.

Devlin (1991), in the seminal work Logic and information, proposes the infon as a standard more appropriate to measure the amount of information contained in a message. An infon is a given amount of data in a particular context, regarding context as an ordered set of $n$ numbers, used to characterize a situation. According to Devlin (1991), it would not be possible to evaluate the content of a message without regarding it as situated, within its context.

Similarly, as for knowledge, Herbert Simon (1981), in As ciências do artificial, is relatively premonitory, going beyond the difficulties for measuring information. He proposes a new unit to measure knowledge, named chunk, which had the structure of a short narrative, a micro-story. From the work by Simon (1981) extremely current implications are derived, related to the fact that knowing is always knowing the engine through which meaning is built, i.e. the narrative.

Technology does not seem to have carried on such original initiatives, and the bit is still the standard used for 
evaluating data, information, knowledge... and the theoretical reflections on this theme also tend to lack deeper references about it.

A third trend of challenges is facing in a radical way the specificity of knowledge as a value in the economic sense. Regardless of how attractive is the approach to themes such as those of the journal Entropia, unveiling the void or the incongruity of growth as an end, or that related to the concept of commons, with an emphasis on the characterization of goods to be freely shared by all, there are crucial peculiarities to consider in the case of knowledge.

As already registered, in the current scenario, the very idea of knowledge property, as well as the conception of authorship, is put into question. It is increasingly needed a new conceptualization of author and authorship, in line with the dynamics of information flow in today's world. At no time the creation has taken place as a combination made by Lavoisier, a mere copy of what already exists, nor in an absolutely original way, as a divine creation. It already seems clear enough, however, that the copy is not an enemy of creation, and a characterization of the author has gained momentum, who now occupies a new position, between God and Lavoisier. Especially when it comes to scientific papers, the acknowledgment, authorship as a responsibility should already be more than enough.

Regarding the commons, Ostrom's great merit by including knowledge on the list of goods to be freely shared, just as the air or water we have, cannot minimize certain radical distinctions: although it is unevenly distributed, knowledge is not a good to be saved, whose use needs to be dosed.
After all, as pointed out by Ostrom herself, the fact that someone uses Einstein's Theory of Relativity does not hinder someone else from using it. Knowledge is a value, but it is not like a gold pot to be disputed, divided in a merely accounting way, or appropriated by some to the detriment of others. When we seek knowledge along with others, all of us can get there, understanding may be fully achieved by everyone, with no games of losses and gains. A significant key to address this issue is the fact that, as a theory, as a view that leads to understanding, knowledge does not agree with hypocrisy: human integrity presupposes that, whoever opens her/his eyes to a situation, cannot pretend to see nothing anymore.

\section{REFERENCES}

Devlin, K. (1991). Logic and information. Cambridge: Cambridge University Press.

Latouche, S. (2006, outubro). "La décroissance: un projet politique". Entropia. Revue detude théorique et politique de la décroissance, 1, pp. 9-21.

Ostrom, E., \& Hess, C. (2011). Understanding knowledge as a commons. Cambridge, MA: The MIT Press.

"Pourquoi Entropia?" [Editorial]. (2006). Entropia. Revue détude théorique et politique de la décroissance. 1, p. 3.

Simon, H. (1981). As ciências do artificial. Coimbra: Arménio Amado. 